\title{
Strategi Pengembangan Usaha Pembenihan Ikan Nila di Balai Benih Ikan (BBI) Lokal Gunung Manau Kecamatan Batuman di Kabupaten Balangan
}

\section{(Business Development Strategy Of Tilapia Hatchery Local Fish Breeding Center (FBC) Gunung Manau Batumandi District Balangan Regency)}

\author{
Arief Hidayatullah ${ }^{1)}$ \& Hairun ${ }^{2)}$ \\ Program Studi Agribisnis, Sekolah Tinggi Ilmu Pertanian Amuntai \\ 1)arief_stiperamuntai@yahoo.com \\ ${ }^{2)}$ hairun@yahoo.com
}

\begin{abstract}
ABSTRAK
Penelitian bertujuan mengidentifikasi faktor internal dan eksternal, merumuskan alternatif strategi, dan prioritas strategi dalam mengembangkan bisnis pembenihan nila di Balai Benih Ikan (BBI) Lokal Gunung Manau Kecamatan Batumandi Kabupaten Balangan. Metode dasar yang digunakan adalah metode deskriptif dan dilakukan dengan teknik survei. Data yang digunakan dalam penelitian ini adalah data primer dan sekunder. Metode analisis data yang digunakan (1) Analisis SWOT, (2) IE dan matriks SWOT (3) matriks QSP. Hasil penelitian mengungkapkan bahwa (1) kekuatan utama yang mendasar adalah sarana produksi mudah dijangkau, (2) kelemahan utama adalah pemasaran di luar daerah masih kurang. (3) Peluang utama mendapatkan bantuan dari pemerintah. (4) Sedangkan ancaman mendasar adalah efek dari musim kemarau. (5) Berdasarkan matriks IE, maka strateginya adalah penetrasi pasar dan pengembangan produk. (6) Hasil matriks SWOT dari strategi alternatif yang diterapkan adalah menjaga kualitas benih dan meningkatkan produksi melalui peningkatan penerapan Standar Operasional Prosedur (SOP), Pemanfaatan teknologi pemrosesan probiotik pakan dan pelatihan pakan serta menambah jumlahnya, meningkatkan kinerja petugas teknis dalam mengelola penyemaian bisnis dengan memberikan dorongan, pemantauan dan evaluasi serta hubungan kerja sama pihak lembaga terkait. (7) Strategi prioritas yang dapat diterapkan adalah meningkatkan kinerja petugas teknis.
\end{abstract}

Kata Kunci : Pembenihan, ikan, nila, strategi, BBI.

\section{ABSTRACT}

The research aims to identify internal and external factors, formulate alternative strategies, and prioritize strategies in developing the tilapia hatchery business at the Gunung Manau Local Fish Breeding Center, Batumandi District, Balangan Regency. The basic method used is descriptive method and carried out by survey techniques. The data used in this study are primary and secondary data. Data analysis methods used (1) SWOT Analysis, (2) IE and SWOT matrix (3) QSP matrix. The results of the study reveal that (1) the main underlying strength is easily accessible production facilities, (2) the main disadvantage is that marketing outside the region is still lacking. (3) The main opportunity to get assistance from the government. (4) Whereas the fundamental threat is the effect of the dry season. (5) Based on the IE matrix, the strategy is market penetration and product development. (6) The results of the SWOT matrix from the alternative strategies implemented are maintaining seed quality and increasing production through increased application of Standard Operating Procedures (SOP), Utilization of feed probiotic processing technology and feed training and increasing the number, improving the performance of technical officers in managing business seeding by providing encouragement, monitoring and evaluation as well as cooperative relations of the related institutions. (7) The priority strategy that can be applied is to improve the performance of technical officers.

Keywords: Hatchery, fish, indigo, strategy, BBI.

\section{PENDAHULUAN}

Produksi perikanan Kalimantan Selatan pada tahun 2005 sebesar 199.859,7 ton, yang terdiri dari produksi ikan laut sebanyak 136.519,9 ton, produksi ikan perairan umum sebanyak 49.622,90 ton, dan produksi dari usaha budidaya sebanyak 
13.726,9 ton. Ssedangkan perkembangan jumlah armada perikanan Kalimntan Selatan pada tahun 2005 adalah 9.639 buah kapal/perahu motor, 1.042 buah $\mathrm{kapal} /$ perahu tanpa motor, 361 buah kapal/perahu tempel (Antara, 2014)

Produksi perikanan tangkap

Kabupaten Balangan di perairan umum berupa rawa sebesar 304,1 ton dan sungai sebesar 410,5 ton. Sementara itu dari hasil perikanan budidaya di karamba sebanyak 94,8 ton dan kolam sebanyak 27,2 ton (Statistik Perikanan, 2010).

Melalui program pengembangan perikanan diarapkan perluasan lahan budidaya dapat memenuhi target yang diinginkan. Langkah-langkah yang diambil untuk pengembangan potensi perikanan berupa perluasan areal kolam, karamba dan jaring apung di wilayah potensial seperti sungai, kolam, dan rawa.

Dalam kegiatan usaha budidaya, salah satunya adalah usaha pembenihan. Usaha pembenihan merupakan kegiatan pemeliharaan induk untuk menghasilkan telur sampai menhasilkan larva / benih. Kegiatan pembenihan ikan di Balai Benih Ikan (BBI) Lokal Gunung Manau dimulai dari persiapan produksi sampai pemasaran ke petani pembudidaya. Peluang untuk meningkatkan kualitas dan kuantitas benih ikan nila di Balai Benih Ikan (BBI) Lokal masih cukup besar, antara lain melalui perbaikan paket teknologi pembenihan dan penambahan jumlah kolam. Oleh karena itu perlu adanya pengembangan usaha pembenihan ikan nila yang bertujuan untuk mencapai produksi optimal.

Tabel 1. Potensi lahan pengembangan perikanan budidaya 2010-2014 Kabupaten Balangan

\begin{tabular}{ccccccc}
\hline \multirow{2}{*}{ No } & \multirow{2}{*}{ Areal } & 2010 & 2011 & 2012 & 2013 & 2014 \\
\cline { 3 - 7 } & & 5,25 & 5,8 & 6,35 & 6,9 & 7,2 \\
1 & Kolam & 0,65 & 1,2 & 1,45 & 1,85 & 2,15 \\
2 & Danau/waduk(KJA) & 175 & 210 & 235 & 285 & 325 \\
3 & Sungai (karamba) & 0 & 0 & 0 & 0 & 0 \\
4 & Lainnya & 180,9 & 217 & 242,8 & 293,75 & 334,35 \\
\hline & Jumlah &
\end{tabular}

Sumber : Dinas Pertanian Tanaman Pangan Hortikultura Peternakan dan Perikanan Kabupaten Balangan 2010-2014.

Kontribusi produksi perikanan air tawar dari kegiatan budidaya setiap tahunnya masih relatif rendah, untuk mempertahankan dan kemungkinan meningkatkan produksi perikanan air tawar telah dilakukan program intensifikasi, baik yang dilakukan pada budidaya perkolaman, budidaya sawah maupun keramba.

Tabel 2. Target produksi dan areal perikanan budidaya 2010 - 2014 Kabupaten Balangan

\begin{tabular}{ccccccc}
\hline \multirow{2}{*}{ No } & \multirow{2}{*}{ Komoditas } & \multicolumn{5}{c}{ Produksi (ha) } \\
\cline { 3 - 7 } & & 2010 & 2011 & 2012 & 2013 & 2014 \\
\hline 1 & Mas & 28,75 & 36,6 & 61,15 & 61,15 & 77,3 \\
2 & Nila & 124,3 & 140,65 & 172,15 & 172,15 & 181,55 \\
3 & Patin & 8,9 & 15,5 & 21,65 & 38,3 & 52,1 \\
4 & Lainnya & 2,25 & 6,65 & 16,4 & 16,4 & 22,9 \\
& Jumlah & 164,2 & 199.3 & 288 & 288 & 333,85 \\
\hline \multirow{2}{*}{ Sumber $:$ Dinas Pertanian Tanaman pangan } & Hortikultura & Peternakan dan Perikanan & Kabupaten \\
& Balangan 2010-2014. & &
\end{tabular}

Dari tabel di atas dapat dilihat peningkatan produksi dari tahun 2010 2014 sebesar 203,32\%. Dalam hal ini untuk mencapai target produksi perikanan $353 \%$ diperlukan pengembangan potensi lahan budidaya. Dalam kegiatan usaha budidaya, salah satunya adalah usaha pembenihan. Usaha pembenihan merupakan kegiatan 
pemeliharaan induk untuk menghasilkan telur sampai menhasilkan larva / benih. Kegiatan pembenihan ikan di Balai Benih Ikan (BBI) Lokal Gunung Manau dimulai dari persiapan produksi sampai pemasaran ke petani pembudidaya. Teknik Pembenihan ikan di Balai Benih Ikan (BBI) GunungManau dilakukan melalui pemijahan secara buatan pada ikan patin dan baung, semi buatan pada ikan lele dan betok, dan secara alami pada ikan mas dan nila.

Program-program yang telah dilakukan dalam bidang perikanan masih perlu ditindaklanjuti, agar lebih terarah dan sesuai dengan potensi serta daya dukung lingkungan baik secara teknis, ekonomis, maupun sosial. Sampai saat ini pembenihan ikan nila di Balai Benih Ikan (BBI) Lokal Gunung Manau masih eksis, namun menghadapi kendala seprti masih kurangnya sarana dan prasarana sebagai penunjang kegiatan pembenihan dan masih banyaknya permintaan benih yang belum bisa terpenuhi karena persediaan benih belum mencukupi.

Untuk itu diperlukan pengembangan usaha budidaya perikanan melalui peningkatan produksi dari kultivan yang biasa dibudidayakan atau pengembangan jenis komoditas baru dan aplikasi teknologi budidaya pembenihan yang sesuai denngan kondisi dan lingkungan perkolaman yang ada di Balai benih Ikan (BBI) Lokal Gunung Manau baik secara teknis, ekologis, maupun ekonomi.

Tabel 3. Perkembangan produksi benih ikan nila di Balai Benih Ikan (BBI) Lokal Gunung Manau Kecamatan Batumandi Kabupaten Balangan

\begin{tabular}{cccc}
\hline Tahun & Komoditas & Jumlah Produksi & Total \\
\hline \multirow{2}{*}{2010} & Nila gift & 47.150 & 51.950 \\
& Nila gesit & 4.800 & \\
& Nila gift & 107.386 & 286.386 \\
\multirow{2}{*}{2011} & Nila gesit & 179.000 & \\
& Nila gift & 73.150 & 289.750 \\
2013 & Nila gesit & 216.600 & 304.810 \\
& Nila gift & 263.310 & \\
2014 & Nila gesit & 41.500 & 178.000 \\
\hline
\end{tabular}

Sumber : Balai Benih Ikan (BBI) Lokal Gunung Manau (2014).

Berdasarkan tabel di atas dapat dilihat bahwa produksi benih hasil pembenihan ikan nila di Balai Benih Ikan (BBI) Lokal Gunung Manau mengalami peningkatan sampai tahun 2013, namun pada tahun 2014 produksi benih mengalami penurunan. Secara rinci produksi benih nila gift pada tahun 2011 mengalami peningkatan dan pada tahun 2012 benih nila gift mengalami penurunan, namun pada tahun 2013 benih nila gift mengalami peningkatan. Terjadinya penurunan nila gift tahun 2012 disebabkan menurunnya masa produktif induk, selainkan itu adanya kematian induk nila gift karena kondisi alam yang menyebabkan terjadinya kemarau sehingga persediaan air menjadi kurang. Sedangkan produksi benih nila gesit sampai tahun 2012 produksi mengalami peningkatan yang signifikan, namun pada tahun 2013 benih nila gesit mengalami penurunan. Terjadinya penurunan produksi benih nila gesit juga tidak lepas dari menurunnya kualitas masa produktif induk, juga dikarenakan kendala musim kemarau. Pada tahun 2014 produksi benih jauh mengalami penurunan. Sedangkan tahun 2014 tidak adanya pengadaan induk, karena masa produktif induk selama 2 tahun yang terhitung dari tahun 2013. Terjadi penurunan produksi tahun 2014 juga tidak lepas mulai menurunnya kualitas induk, selain itu, tahun 2014 terjadinya kemarau yang sangat panjang sehingga air saluran kolam tidak bisa mengalir karena air dari sungai bendungan sangatlah surut yang 
menyebabkan induk mengalami kematian secara masal.

Kualitas dan kuantitas benih ikan nila yang dihasilkan sangat ditentukan oleh penerapan teknologi yang digunakan. Cakupan teknologi yang dimaksud adalah teknologi produksi, panen dan pasca panen. Teknologi produksi meliputi pemilihan induk unggul, pemeliharaan benih, input berupa pakan, obat-obatan dan plastik pembungkus. Teknologi panen meliputi ciri dan umur panen serta cara panen. Sedangkan teknologi pasca panen antara lain meliputi penyimpanan, pengangkutan dan grading.

Peluang untuk meningkatkan kualitas dan kuantitas benih ikan nila di Balai Benih Ikan (BBI) Lokal masih cukup besar, antara lain melalui perbaikan paket teknologi pembenihan dan penambahan jumlah kolam. Balai Benih Ikan (BBI) Lokal Gunung Manau mempunyai kriteria lokasi yang cocok untuk usaha pembenihan ikan nila yaitu potensi berupa ketersediaan lahan yang subur dan air yang melimpah pada saat musim hujan maka pengembangan usaha pembenihan ikan nila merupakan peluang yang baik. Oleh karena itu perlu adanya pengembangan usaha pembenihan ikan nila yang bertujuan untuk mencapai produksi optimal.

Tujuan penelitian adalah untuk (i) mengidentifikasi faktor internal dan faktor eksternal (ii) erumuskan alternatif strategi pengembangan usaha pembenihan ikan nila (iii) menentukan prioritas strategi pengembangan usaha pembenihan ikan nila.

\section{METODE PENELITIAN}

\section{Tempat dan Waktu}

Penelitian ini dilaksanakan di Balai Benih Ikan (BBI) Lokal Gunung Manau Kecamatan Batumandi Kabupaten Balangan Bulan Maret-Mei 2015.

\section{Jenis dan Sumber Data}

Jenis dan sumber data yang digunakan adalah data primer dan sekunder.

\section{Analisis Data \\ Pemberian Bobot Setiap faktor (Internal dan Eksternal) \\ 3 = Jika faktor horizontal lebih penting dari pada faktor vertikal \\ 2 = Jika faktor horizontal sama penting dari pada faktor vertikal \\ 1 = Jika faktor horizontal kurang penting dari pada faktor vertikal}

Tabel 4. Penilaian bobot faktor strategis internal pembenihan ikan nila

\begin{tabular}{ccccccc}
\hline Faktor Strategis Internal & A & B & C & $\ldots .$. & Total & Bobot \\
\hline A & & & & & & \\
B & & & & & & \\
C & & & & & & \\
$\ldots .$. & & & & & & \\
Total & & & & & & \\
Sumber : David dalam Umar (2010) & & & &
\end{tabular}

Sumber : David dalam Umar (2010)

Tabel 5. Penilaian bobot faktor strategis eksternal pembenihan ikan nila

\begin{tabular}{ccccccc}
\hline Faktor Strategis Internal & A & B & C & $\ldots$. & Total & Bobot \\
\hline A & & & & & & \\
B & & & & & & \\
C & & & & & & \\
$\ldots .$. & & & & & & \\
Total & & & & & & \\
\hline
\end{tabular}

Sumber : David dalam Umar (2010)

Perkalian Bobot dan Peringkat
Total skor pembobotan berkisar antara 1 sampai 4 dengan rata-rata 2,5. Total skor EFE/IFE dikelompokkan dalam (3,0 - 
4,0) berarti usaha pembenihan ikan nila merespon kuat terhadap peluang dan ancaman/kelemahan ada, sedang $(2,0-2,99)$ berarti usaha pembenihan ikan nila merespon sedang terhadap peluang/kekuatan dan ancaman/kelemahan yang ada dan lemah, $(1,0-1,99)$ berarti usaha pembenihan ikan nila tidak dapat merespon peluang/kekuatan dan ancaman/kelemahan yang ada.

\section{Matriks IE (Internal-Eksternal)}

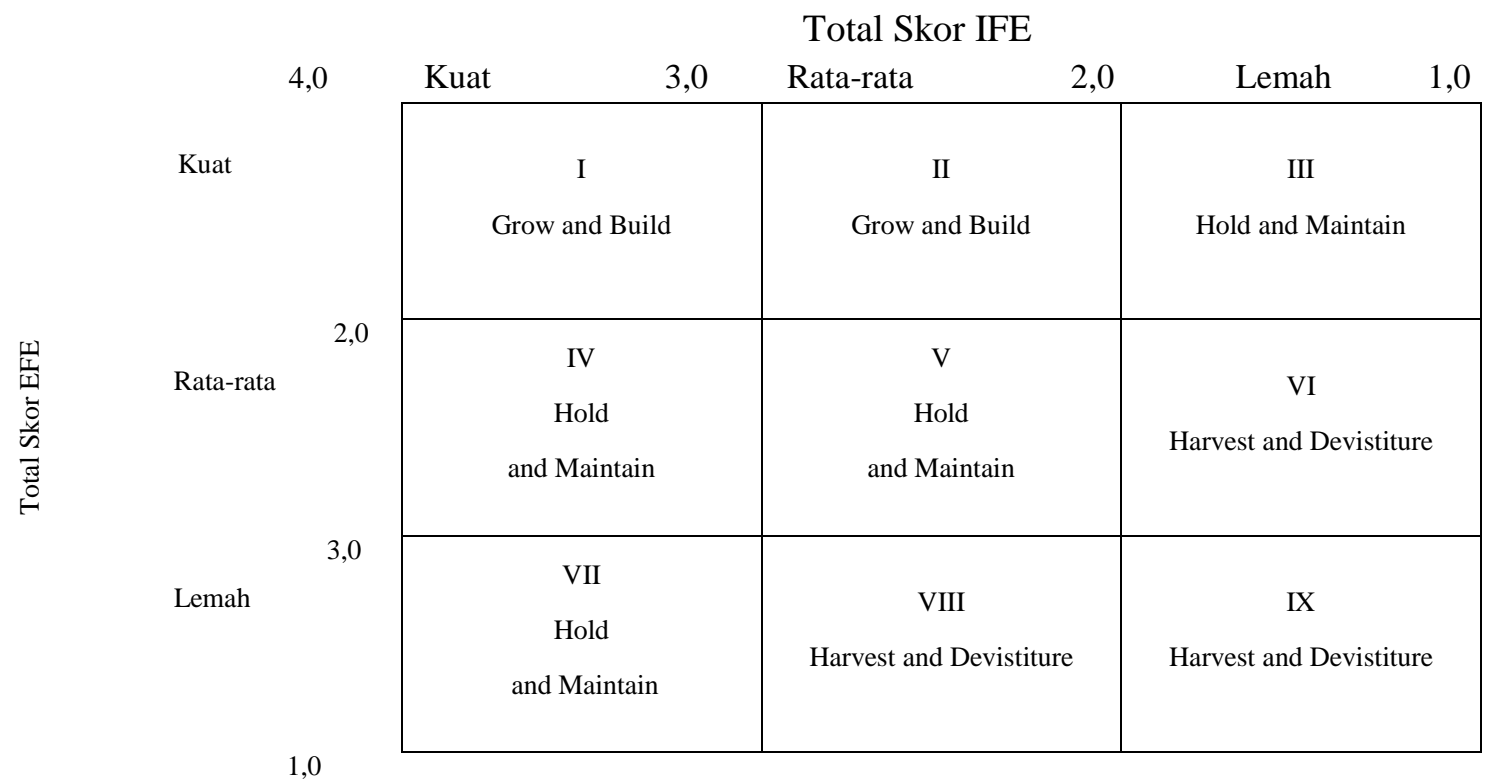

Gambar 2.Matriks IE (Internal-Eksternal)

\section{Matriks SWOT}

Tabel 6. Matriks SWOT

\begin{tabular}{|c|c|c|}
\hline & $\begin{array}{c}\text { Strenght (S) } \\
\text { Tentukan 5-10 } \\
\text { faktor-faktor kekuatan internal }\end{array}$ & $\begin{array}{c}\text { Weakness }(\mathrm{W}) \\
\text { Tentukan 5-10 faktorfaktor } \\
\text { Kelemahan internal } \\
\end{array}$ \\
\hline $\begin{array}{l}\text { Opportunities }(\mathrm{O}) \\
\text { Tentukan 5-10 faktorfaktor } \\
\text { peluang eksternal }\end{array}$ & $\begin{array}{c}\text { Strategi S-O } \\
\text { Ciptakan strategi } \\
\text { yang menggunakan kekuatan } \\
\text { untuk memanfaatkan peluang }\end{array}$ & $\begin{array}{c}\text { Strategi W-O } \\
\text { Ciptakan strategi yang } \\
\text { meminimalkan } \\
\text { kelemahan untuk memanfaatkan } \\
\text { peluang } \\
\end{array}$ \\
\hline $\begin{array}{c}\text { Threats }(\mathrm{T}) \\
\text { Tentukan 5-10 faktorfaktor } \\
\text { ancaman } \\
\text { eksternal }\end{array}$ & $\begin{array}{c}\text { Strategi S-T } \\
\text { Ciptakan strategi } \\
\text { yang menggunakan kekuatan } \\
\text { untuk mengatasi ancaman }\end{array}$ & $\begin{array}{c}\text { Strategi W-T } \\
\text { Ciptakan strategi yang } \\
\text { meminimalkan } \\
\text { kelemahan dan } \\
\text { menghindari ancaman }\end{array}$ \\
\hline
\end{tabular}

Sumber: Rangkuti (2001) 


\section{HASIL DAN PEMBAHASAN}

Identifikasi Faktor Kekuatan, Kelemahan, Peluang, dan Ancaman

Tabel 7. Identifikasi kekuatan, kelemahan, peluang, dan ancaman dalam pengembangan usaha pembenihan ikan nila di Balai Benih Ikan (BBI) Lokal Gunung Manau.

\begin{tabular}{|c|c|c|}
\hline Faktor Internal & Kekuatan & Kelemahan \\
\hline Kondisi keuangan & - Memliki modal yang cukup & - \\
\hline Sumber Daya manusia & $\begin{array}{l}\text { - Memiliki SDM yang } \\
\text { berkompetensi dibidang perikanan }\end{array}$ & \\
\hline Pemasaran & $\begin{array}{l}\text { - Memiliki sertifikat CPIB dari pusat } \\
\text { - Kontinuitas produksi }\end{array}$ & $\begin{array}{l}\text { - Pemasaran keluar daerah masih } \\
\text { kurang } \\
\text { - Harga PAD cukup tinggi }\end{array}$ \\
\hline Produksi/operasional & - Sarana produksi mudah dijangkau & $\begin{array}{l}\text { - Pengelolaan masih kurang optimal } \\
\text { - Keterbatasan jumlah kolam }\end{array}$ \\
\hline Manajemen & - & $\begin{array}{l}\text { - Belum tertata rapi administrasi } \\
\text { tatausaha pembenihan }\end{array}$ \\
\hline Faktor Eksternal & Peluang & Ancaman \\
\hline Kondisi perekonomian & - Permintaan semakin meningkat & - Kenaikan harga pakan \\
\hline Sosial dan Budaya & $\begin{array}{l}\text { - Kondisi lingkungan yang aman dan } \\
\text { terkendali } \\
\text { - Adanya bantuan pemerintah }\end{array}$ & - \\
\hline Politik dan Hukum & $\begin{array}{l}\text { - Adanya pelatihan bagi petugas } \\
\text { teknis }\end{array}$ & - \\
\hline Teknologi & - Penggunaan teknologi probiotik & $\begin{array}{l}\text { - Perkembangan teknologi dari luar } \\
\text { lebih modern }\end{array}$ \\
\hline Persaingan & - & $\begin{array}{l}\text { - Harga benih ikan dari luar lebih } \\
\text { murah } \\
\text { - Adanya produk pengganti yang } \\
\text { menjadi pesaing }\end{array}$ \\
\hline Kondisi Alam & - & - Pengaruh musim kemarau \\
\hline
\end{tabular}

\section{Perumusan Alternatif Strategi}

Matriks IFE (Internal Factor Evaluation)
Hasil perhitungan nilai skor dari bobot dan rating dari setiap faktor dapat dilihat pada Tabel

Tabel 8. Hasil perhitungan skor Matiks IFE (Internal Factor Evaluation)

\begin{tabular}{lccc}
\hline \multicolumn{1}{c}{ KETERANGAN } & BOBOT & RATING & SKOR \\
\hline KEKUATAN & & & \\
\hline Benih memiliki sertifikat dari pusat & 0,087 & 4 & 0,348 \\
Kontinuitas produksi & 0,094 & 3 & 0,282 \\
Sarana produksi mudah dijangkau & 0,109 & 4 & 0,436 \\
SDM yang berkompetensi dibidang perikanan & 0,131 & 3 & 0,393 \\
Memiliki modal yang cukup & 0,091 & 4 & 0,364 \\
\hline KELEMAHAN & & & 0,312 \\
\hline Belum tertata rapi administrasi tatausaha pembenihan & 0,104 & 3 & 0,111 \\
Keterbatasan jumlah kolam & 0,111 & 1 & 0,228 \\
Pengelolaan masih kurang optimal & 0,114 & 2 & 0,204 \\
Harga PAD sukup tinggi & 0,068 & 3 & 0,078 \\
Pemasaran ke luar daerah masih kurang & 0,078 & 1 & 2,756 \\
\hline \multicolumn{2}{c}{ Total } & 1 & \\
\hline
\end{tabular}


Matriks EFE (Eksternal Factor Evaluation)

Tabel 9. Hasil perhitungan skor matriks EFE (Eksternal Factor Evaluation)

\begin{tabular}{lccc}
\hline \multicolumn{1}{c}{ KETERANGAN } & BOBOT & RATING & SKOR \\
\hline PELUANG & & & \\
\hline Adanya bantuan dari pemerintah & 0,131 & 4 & 0,524 \\
Permintaan semakin meningkat & 0,083 & 4 & 0,332 \\
Adanya pelatihan bagi petugas teknis & 0,114 & 3 & 0,342 \\
Kondisi yang aman dan terkendali & 0,101 & 3 & 0,303 \\
Penggunaan teknologi pakan probiotik & 0,087 & 4 & 0,348 \\
\hline ANCAMAN & 0,075 & 2 & 0,150 \\
\hline Harga benih ikan nila dari luar lebih murah & 0,089 & 2 & 0,178 \\
Kenaikan harga pakan & 0,103 & 2 & 0,206 \\
Perkembangan teknologi dari luar lebih modern & 0,095 & 2 & 0,190 \\
Adanya produk pengganti yang menjadi pesaing & 0,114 & 1 & 0,114 \\
Pengaruh musim kemarau & 1 & & 2,687 \\
\hline \multicolumn{1}{c}{ Total } &
\end{tabular}

\section{Matriks IE (Internal-Eksternal)}

Berdasarkan perhitungan pembobotan pada matriks IFE dan EFE, diperoleh skor total matriks IFE sebesar 2,756 sedangkan skor total matriks EFE adalah 2,687.

\section{Matriks IE (Internal-Eksternal)}

Berdasarkan perhitungan pembobotan pada matriks IFE dan EFE, diperoleh skor total matriks IFE sebesar 2,756 sedangkan skor total matriks EFE adalah 2,687 .

TOTAL SKOR IFE

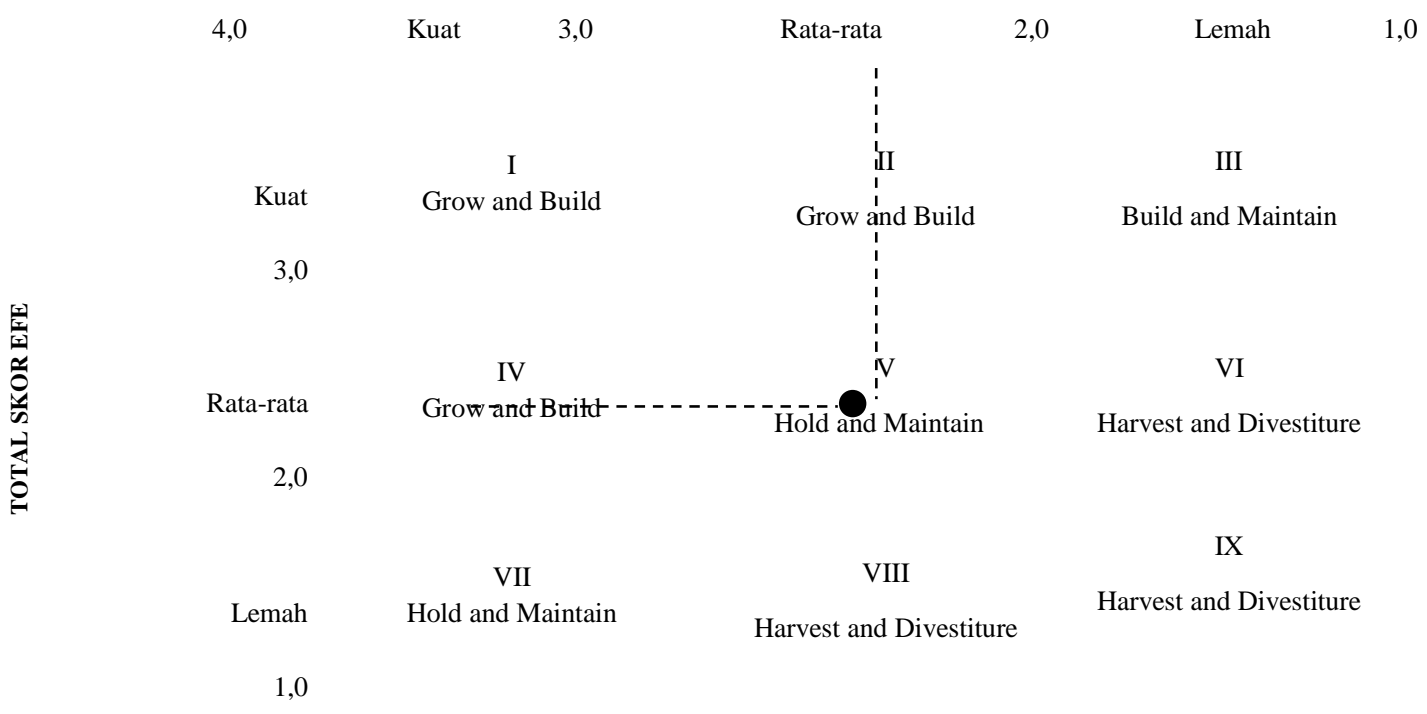

Gambar 3. Matriks IE (Internal-Eksternal) Analisis Hasil Penelitian

Nilai rata-rata matriks IFE yaitu sebesar 2,756 dan nilai rata-rata matriks EFE yaitu 2,687, dari nilai rata-rata tersebut menempatkan Balai Benih Ikan (BBI) Lokal
Gunung Manau pada posisi kuadran V atau Hold and Maintain atau strategi pertahankan dan pelihara. Strategi yang tepat digunakan untuk Balai Benih Ikan (BBI) Lokal Gunung 
Manau adalah dengan strategi penetrasi

pasar, dan pengembangan produk.

\section{Matriks SWOT}

Tabel 10. Alternatif strategi matriks SWOT pengembangan usaha pembenihan ikan nila di Balai Benih Ikan (BBI) Lokal Gunung Manau.

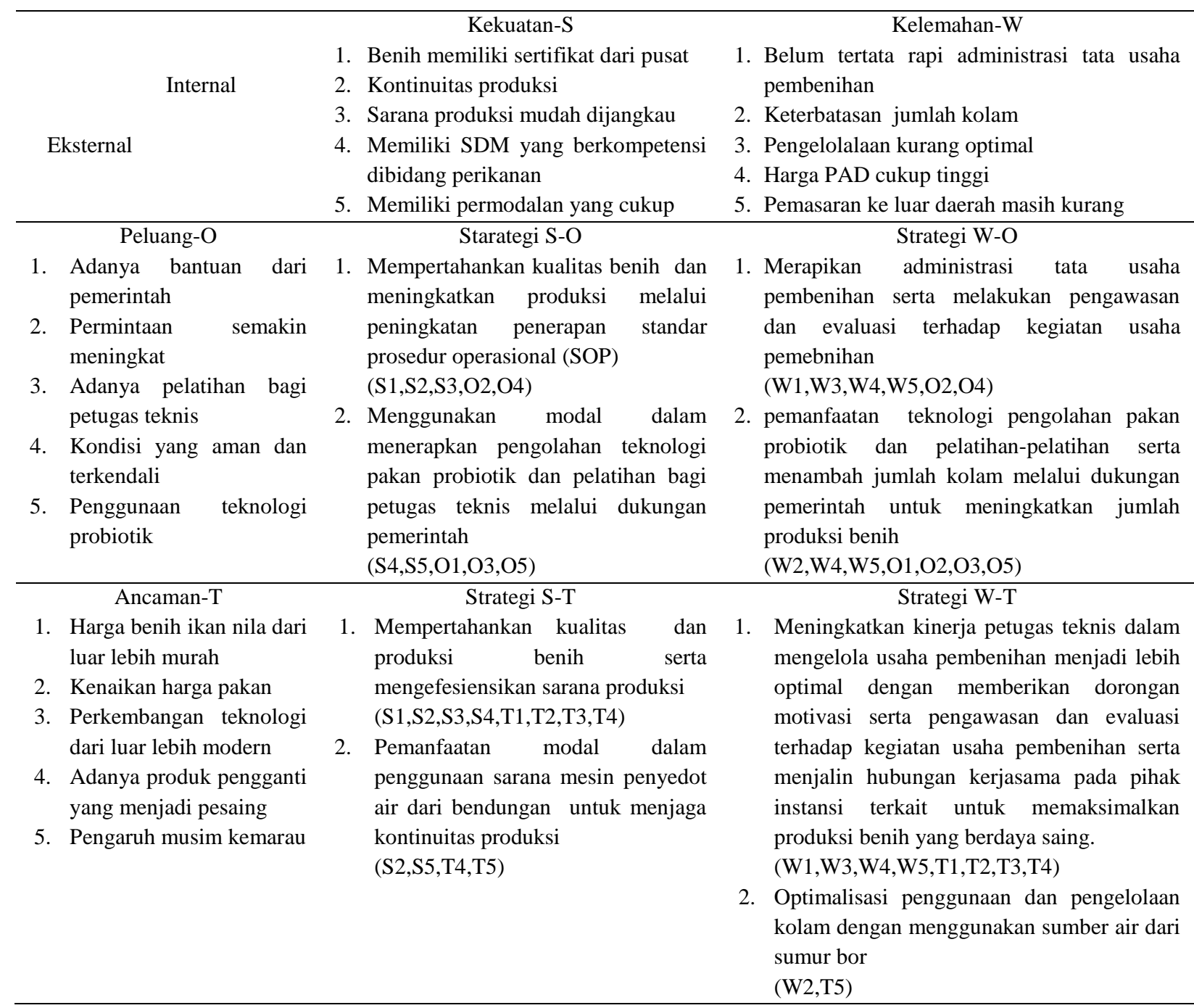

\section{Prioritas Strategi}

1) Mempertahankan kualitas benih dan meningkatlkan produksi melalui peningkatan penerapan Standar Operasional Prosedur (SOP).

2) Pemanfaatan teknologi pengolahan pakan probiotik dan pelatihan-pelatihan serta menambah jumlah kolam melalui dukungan pemerintah untuk meningkatkan jumlah produksi.

3) Meningkatkan kinerja petugas teknis dalam mengelola usaha pembenihan menjadi lebih optimal dengan memberikan dorongan motivasi serta pengawasan dan evaluasi terhadap kegiatan usaha pembenihan serta menjalin hubungan kerja sama pada pihak instansi terkait untuk memaksimalkan produksi yang berdaya saing.

Strategi terbaik yang dapat diterapkan dalam mengembangkan usaha pembenihan ikan nila di Balai Benih Ikan (BBI) Lokal gunung Manau Kecamatan Batumandi Kabupaten Balangan bedasarkan matris QSP adalah Strategi III yaitu Meningkatkan kinerja petugas teknis dalam mengelola usaha pembenihan menjadi lebih optimal dengan memberikan dorongan motivasi serta pengawasan dan evaluasi 
terhadap kegiatan usaha pembenihan serta menjalin hubungan kerja sama pada pihak instansi terkait untuk memaksimalkan produksi yang berdaya saing dengan nilai TAS (Total Attractive Score) sebesar 6,933. Pelaksanaan alternatif strategi yang

Tabel 12. QSPM (Quantitative Strategic Planning Matrix) Pengembangan Usaha Pembenihan Ikan Nila di Balai Benih Ikan (BBI) Lokal Gunung Manau. tertinggi, kemudian tertinggi kedua, dan diikuti strategi urutan berikutnya sampai nila TAS strategi terkecil. Hasil perhitungan analisis matriks QSP dapat dillihat pada Tabel 10.

\begin{tabular}{|c|c|c|c|c|c|c|c|}
\hline \multirow{3}{*}{ Faktor-Faktor Kunci } & \multirow{3}{*}{ Bobot } & \multicolumn{6}{|c|}{ Alternatif Strategi } \\
\hline & & \multicolumn{2}{|c|}{ Strategi I } & \multicolumn{2}{|c|}{ Strategi II } & \multicolumn{2}{|c|}{ Strategi III } \\
\hline & & AS & TAS & $\mathrm{AS}$ & TAS & $\mathrm{AS}$ & TAS \\
\hline \multicolumn{8}{|l|}{ Kekuatan } \\
\hline Benih memilki sertifikat dari pusat & 0,087 & 4 & 0,348 & 4 & 0,348 & 4 & 0,348 \\
\hline Kontinuitas Produksi & 0,094 & 4 & 0,376 & 4 & 0,376 & 4 & 0,376 \\
\hline Sarana produksi mudah dijangkau & 0,109 & 3 & 0,327 & 3 & 0,327 & 4 & 0,436 \\
\hline SDM yang berkompetensi dibidang perikanan & 0,131 & 4 & 0,524 & 4 & 0,524 & 4 & 0,524 \\
\hline Memiliki modal yang cukup & 0,091 & 2 & 0,182 & 3 & 0,273 & 2 & 0,182 \\
\hline \multicolumn{8}{|l|}{ Kelemahan } \\
\hline $\begin{array}{l}\text { Belum tertata rapi administrasi tatausaha } \\
\text { pembenihan }\end{array}$ & 0104 & 3 & 0,312 & 2 & 0,208 & 3 & 0,312 \\
\hline Keterbatasan jumlah kolam & 0,111 & 4 & 0,444 & 3 & 0,333 & 4 & 0,444 \\
\hline pengelolaan masih kurang optimal & 0,114 & 3 & 0,342 & 3 & 0,342 & 4 & 0,456 \\
\hline Harga PAD cukup tinggi & 0,068 & 2 & 0,136 & 2 & 0,136 & 2 & 0,136 \\
\hline Pemasaran ke luar daerah masih kurang & 0,078 & 2 & 0,156 & 2 & 0,156 & 2 & 0,156 \\
\hline \multicolumn{8}{|l|}{ Peluang } \\
\hline Adanya bantuan dari pemerintah & 0,131 & 4 & 0,524 & 4 & 0,524 & 4 & 0,524 \\
\hline Permintaan semakin meningkat & 0,083 & 4 & 0,332 & 4 & 0,332 & 4 & 0,332 \\
\hline Adanya pelatihan dari petugas teknis & 0,114 & 3 & 0,342 & 4 & 0,456 & 4 & 0,456 \\
\hline Kondisi yang aman dan terkendali & 0,101 & 2 & 0,202 & 2 & 0,202 & 2 & 0,202 \\
\hline Penggunaan teknologi pakan Probiotik & 0,087 & 4 & 0,348 & 4 & 0,348 & 4 & 0,348 \\
\hline \multicolumn{8}{|l|}{ Ancaman } \\
\hline Harga benih ikan dari luar lebih & 0,075 & 4 & 0,300 & 3 & 0,225 & 4 & 0,300 \\
\hline Kenaikan harga pakan & 0,089 & 3 & 0,267 & 4 & 0,356 & 3 & 0,267 \\
\hline Perkembangan teknologi dari luar lebih modern & 0,103 & 4 & 0,412 & 3 & 0,309 & 4 & 0,412 \\
\hline Adanya produk pengganti yang menjadi pesaing & 0,095 & 4 & 0,380 & 3 & 0,285 & 4 & 0,380 \\
\hline Pengaruh musim kemarau & 0,114 & 2 & 0,228 & 2 & 0,228 & 3 & 0,342 \\
\hline Jumlah Total Nilai DayaTarik & & & 6,482 & & 6,288 & & 6,933 \\
\hline
\end{tabular}

Sumber : Diadopsi dan diolah dari lampiran

\section{KESIMPULAN}

Usaha pembenihan ikan nila di Balai Benih Ikan (BBI) Lokal Gunung Manau kekuatan dalam mengembangkan usaha pembenihan nila yaitu benih memiliki sertifikat dari pusat, kontinuitas produksi, sarana produksi mudah dijangkau, SDM yang berkompetensi dibidang perikanan, memiliki modal yang cukup. Sedangkan kelemahannya yaitu belum tertata rapi administrasi tatausaha pembenihan, keterbatasan jumlah kolam, pengelolaan masih kurang optimal, harga PAD (Pendapatan Asli Daerah) cukup tinggi, pemasaran ke luar daerah masih kurang. Peluang yang dimiliki yaitu adanya 
dari analisis matriks SWOT yang dapat diterapkan dipilih tiga alternatif dalam mengembangkan usaha pembenihan ikan nila di Balai Benih Ikan (BBI) Lokal Gunung Manau yaitu mempertahankan kualitas benih dan meningkatlkan produksi melalui peningkatan penerapan Standar Operasional Prosedur (SOP), pemanfaatan teknologi pengolahan pakan probiotik dan pelatihan-pelatihan serta menambah jumlah kolam melalui dukungan pemerintah untuk meningkatkan jumlah produksi, dan meningkatkan kinerja petugas teknis dalam mengelola usaha pembenihan menjadi lebih optimal dengan memberikan dorongan motivasi serta pengawasan dan evaluasi terhadap kegiatan usaha pembenihan serta menjalin hubungan kerja sama pada pihak instansi terkait untuk memaksimalkan produksi yang berdaya saing.

Berdasarkan analisis matriks QSP, prioritas strategi yang dapat diterapkan dalam mengembangkan usaha pembenihan ikan nila di Balai Benih Ikan (BBI) Lokal Gunung Manau adalah meningkatkan kinerja petugas teknis dalam mengelola usaha pembenihan menjadi lebih optimal dengan memberikan dorongan motivasi serta pengawasan dan evaluasi terhadap kegiatan usaha pembenihan serta menjalin hubungan kerja sama pada pihak instansi terkait untuk memaksimalkan produksi yang berdaya saing.

\section{DAFTAR PUSTAKA}

Antara. 2014. Ikan Lokal Kalsel. https://hasanzainuddin.wordpress.co $\underline{\text { m. }}$. Diakses pada tanggal 14 Maret 2015.

Balai Benih Ikan (BBI) Lokal Gunung Manau. 2014. Data produksi benih ikan nila. Batu Mandi.

Dinas Pertanian Tanaman Pangan Hortikultura Peternakan dan Perikanan Kabupaten Balangan 2014. Laporan Tahunan. Paringin.
Umar. 2010. Desain Penelitian Manajemen Strategik. PT Raja Grafindo Persada. Jakarta.
Dinas Pertanian Tanaman Pangan Hortikultura Peternakan dan Perikanan Kabupaten Balangan 2010-2014

Rangkuti, F. 2001. Analisis SWOT Teknik Membedah Kasus Bisnis. Gramedia Pustaka Utama. Jakarta.

Statisitik Perikanan. 2010. Potensi Perikanan Kabupaten Balangan. http://kelompok10sipt.blogspot.com/ . Diakses pada tanggal 25 Maret 2015. 